\title{
Preconception Care for Improving Perinatal Outcomes: The Time to Act
}

\author{
Hani K. Atrash • Kay Johnson • Myron (Mike) Adams • \\ José F. Cordero · Jennifer Howse
}

Published online: 14 June 2006

(C) Springer Science+Business Media, Inc. 2006

Keywords Women's health · Preconception care · Perinatal outcomes

\section{Introduction}

A healthy baby and a healthy mother are valued hopes and dreams of families of all cultural heritages. National health goals in many countries around the world prioritize infant and maternal mortality and morbidity. In the United States, as in many other industrialized countries, pregnancy outcomes and maternal and infant health indicators have improved dramatically. At the turn of the 20th century, 7.28 women and 96 infants died for every 1,000 babies born alive [1]. By the end of the year 2000 , the maternal mortality rate had decreased to less than 0.08 and infant mortality had decreased to less than 7 deaths per 1,000 live births [2]. These changes were characterized as one of the ten "great public health achievements" of the 20th century [3]. Much of this progress can be attributed to changes in social and living conditions as well as the development and implementation of effective medical interventions. Despite this progress, during the last

The findings and conclusions in this report are those of the authors and do not necessarily represent the views of the Centers for Disease Control and Prevention.

H. K. Atrash $(\square) \cdot$ M. Adams · J. F. Cordero

National Center on Birth Defects and Developmental Disabilities,

Centers for Disease Control and Prevention,

1600 Clifton Rd. NE, E-87, Atlanta, GA 30333

e-mail: hatrash@cdc.gov

K. Johnson

Department of Pediatrics, Dartmouth-Hitchcock Medical center

J. Howse

March of Dimes two decades of the 20th century, even in the presence of significant breakthroughs in medical technology and its application, improvements in maternal and infant pregnancy ouctomes slowed down significantly, and in some cases, outcomes deteriorated. For example, from 1960 to 1980, the maternal mortality rate decreased from 32.1 to 9.4 deaths per 100,000 live births, a decrease of $70.7 \%$. From 1980 to 2000 , the maternal mortality rate decreased only $12.8 \%$, from 9.4 to 8.2 (Figure 1) [2]. At the same time, from 1980 to 2000 , the proportion of babies born preterm, very preterm, low birth weight, and very low birth weight increased by $26 \%, 8.2 \%, 14.7 \%$ and $25.9 \%$, respectively (Figure 2) [4]. However, unlike other maternal and infant health indicators, from 1980 to 2000 the infant mortality rate continued to decrease almost at a similar pace as that from 1960 to 1980 , dropping by $45.2 \%$ from 12.6 to 6.9 infant deaths per 1,000 live births, compared with a drop of $51.5 \%$ from 26.0 to 12.6 per 1,000 live births for 1960 to 1980 (Figure 1) [2]. Finally, it is estimated that the proportion of babies born in the United States who have a serious or major structural defect that can have adverse effects on their health or development continues to be about 3\% [5].

Associated with this slowing rate of improvement (and, in some cases, deterioration) in pregnancy outcomes and maternal and infant health indicators is a shift in the leading causes of infant mortality. In 1960, maternal complications of pregnancy (including complications of placenta, cord, and the membranes) did not appear on the list of the 10 leading causes of infant mortality [1]. By 1980, maternal complications of pregnancy became the fifth leading cause of infant mortality, and the third leading cause of infant death in 2002, after congenital anomalies and low birth weight/preterm delivery [6, 7]. In 2002, congenital anomalies, low birth weight, preterm delivery, and maternal complications of pregnancy accounted for $46.4 \%$ of all infant deaths in the United States 
Fig. 1 Maternal and infant mortality rates, United States, 1960-2002

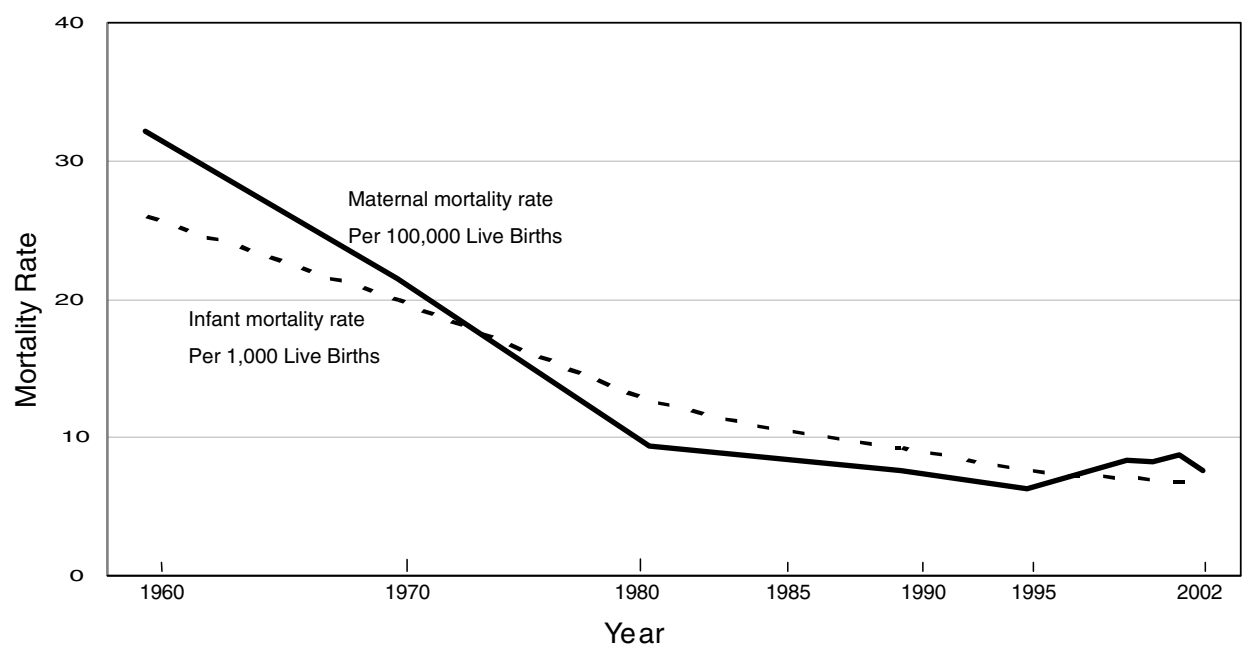

(12,996 infant deaths) (Figure 3) [7]. Although some of these infant deaths might have been prevented through interventions targeted at improving the health of mothers and modifying behaviors contributing to adverse pregnancy outcomes, poor maternal health, behaviors contributing to adverse pregnancy outcomes, and maternal complications of pregnancy continue to be prevalent. For example, $28.6 \%$ of women who gave birth between 1993 and 1997 were reported to have an obstetric complication, $4.1 \%$ had a preexisting medical condition, and $43.0 \%$ experienced some form of maternal morbidity (i.e., an obstetric complication, a preexisting medical condition, a cesarean section, or any combination of the three types of morbidity) [8]. In 2002, 26.1\% of all deliveries were performed using cesarean section, presumably because of maternal or infant complications [8].

\section{Early prenatal care is too late}

One of the reasons that progress in improving pregnancy outcomes has slowed down, and in some cases reversed di- rection, is that we have failed to intervene before pregnancy to detect, manage, modify, and control maternal behaviors, health conditions, and risk factors that contribute to adverse maternal and infant outcomes. Although we know many interventions that, if delivered before pregnancy, could improve pregnancy outcomes, we have failed to make those services and interventions available to couples and women in need. Women of childbearing age suffer from a variety of chronic conditions that could potentially contribute to adverse pregnancy outcomes. For example, in 2002, the U.S. Department of Health and Human Services reported that $6.1 \%$ of women of reproductive age have asthma, $5 \%$ are obese, $3.4 \%$ have cardiac disease, $3.0 \%$ are hypertensive, $9.3 \%$ are diabetic, and $1.4 \%$ have thyroid disorder [9]. Moreover, a substantial proportion of women continue to enter pregnancy with risks proven to contribute to adverse pregnancy outcomes: in 2002, $11.4 \%$ of pregnant women smoked during pregnancy, a risk factor for low birth weight [4]; at the same time, $10.1 \%$ of pregnant women and $54.9 \%$ of women at risk of getting pregnant consumed alcohol, a risk factor for fetal alcohol syndrome [10]. Finally, using
Fig. 2 Percent of all live births that are preterm delivery, very preterm delivery, low birth weight, and very low birth weight, United States, 1980-2002

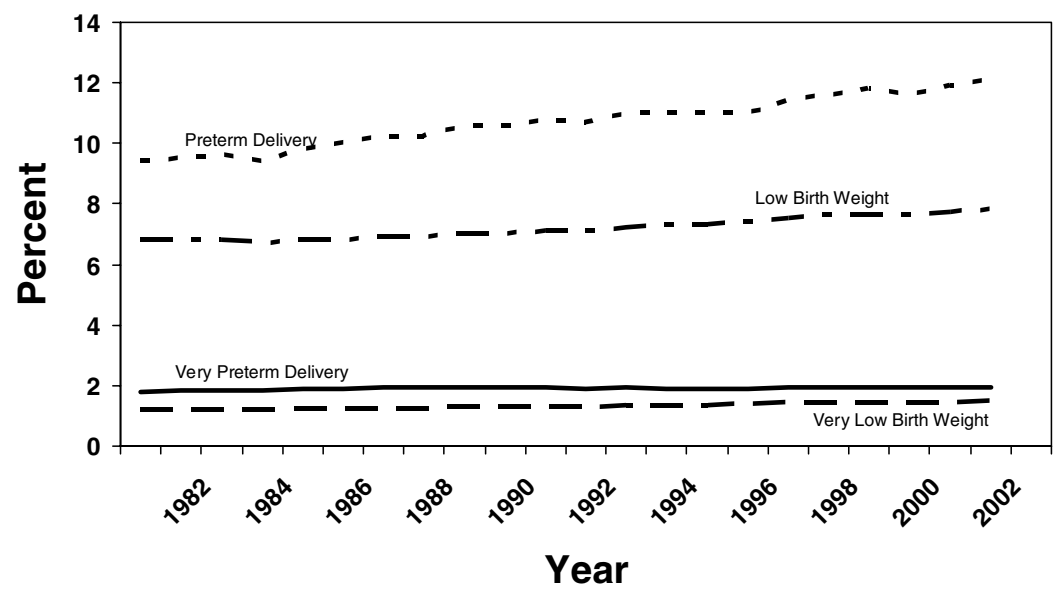




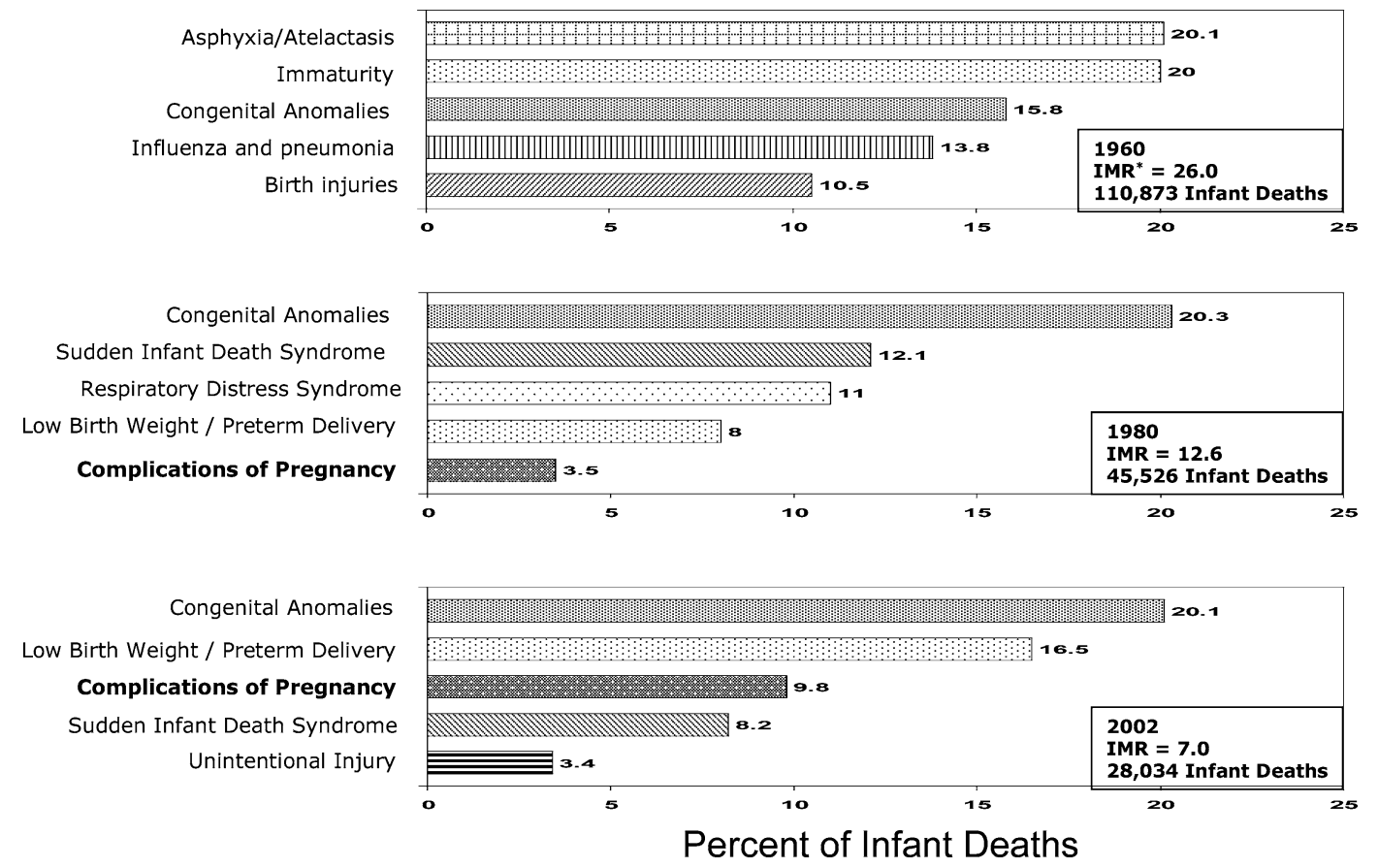

Fig. 3 Leading causes of infant mortality, United States, 1960, 1980, and 2002. *IMR = Infant Mortality Rate

the Perinatal Periods of Risk approach, researchers in three cities (New York City; Tulsa, Oklahoma; and Kansas City, Missouri) concluded that racial and ethnic disparities in fetoinfant mortality were largely related to maternal health, and, interventions to reduce feto-infant mortality should include preconception care and improvements in women's health [11-13].

The prenatal care "revolution" of the 1980s resulted in an increase in the proportion of women receiving early prenatal care (defined as prenatal care begun in the first trimester) [2]. After decreasing from $76.3 \%$ in 1980 to $75.8 \%$ in 1990 , the proportion of women receiving early prenatal care increased to $83.2 \%$ in 2000 [2]. However, for many women, "early prenatal care is too late" [14]. By the time a pregnant woman makes it to her first early prenatal visit, most fetal organs are already been formed, and many interventions to prevent birth defects or adverse maternal and infant outcomes come too late to have any effect. As a result, many national organizations now recommend routine preconception care. For example, the March of Dimes recommends that "as the key physician/primary care provider, the obstetrician/gynecologists must take advantage of every health encounter to provide preconception care and risk reduction before and between conceptions - the time when it really can make a difference" [14]. The American Academy of Pediatrics (AAP) and the American College of Obstetricians and Gynecologists (ACOG) recommend that "all health encounters during a woman's reproductive years, particularly those that are a part of preconception care, should include coun- seling on appropriate medical care and behavior to optimize pregnancy outcomes" [15].

\section{Preconception interventions work}

Interventions designed to lower preconception risks are known collectively as preconception care. These interventions are characterized by the need to start-and sometimes complete-a designated intervention before conception occurs. To simplify matters, ACOG and AAP have grouped the main components of preconception care under four categories of interventions: maternal assessment (e.g., family history, behaviors, obstetric history, general physical exam); vaccinations (e.g., rubella, varicella and hepatitis B); screening (e.g., HIV, STD, genetic disorders); and counseling (e.g., folic acid consumption, smoking and alcohol cessation, weight management) [15]. Many of these interventions are currently available to women and, when indicated, to couples; however, they are not systematically delivered. A comprehensive review of the literature identified a long list of risk factors suggested to be included in comprehensive preconception care (Table 1). The strength of evidence supporting the efficacy of the various components of preconception care varies greatly [16]. Clinical practice guidelines (CPGs) have been developed for reducing the risk related to some of these factors. We identified 14 conditions for which CPGs exist and for which there is scientific evidence demonstrating effectiveness in improving pregnancy outcomes (Table 2) [17-74]. 
Table 1 Risk factors (by Category) identified in the literature as needing attention during the preconception period

Note. This list is not exhaustive
1 Chronic diseases: Diabetes; heart disease; high blood pressure; thyroid disease; asthma; anemia; kidney disease; metabolic and hematological disorders; depression and other mental disorders; autoimmune disease; and physical disability (access)

2 Infectious diseases: Vaccine-preventable diseases (rubella, hepatitis B, varicella, influenza, and tetanus); HIV/AIDS; syphilis, chlamydia, and other sexually transmitted diseases; periodontal disease; toxoplasmosis, and cytomegalic inclusion virus

3 Reproductive concerns: Unplanned pregnancies; contraception; infertility; adverse past pregnancy outcomes (preterm delivery, birth defects, fetal/infant death, maternal complications)

4 Genetic/inherited conditions: Sickle cell anemia; thalassemia; Tay-Sachs disease; fragile X syndrome; Down syndrome; cystic fibrosis; muscular dystrophy; hearing and vision loss associated with genetic predisposition

5 Medications and medical treatment: Prescription medications contraindicated in pregnant women (FDA's Category X Drugs, 117 products in 2001 PDR, antiepileptic drugs, oral anticoagulants for maternal clotting disorders, and Accutane); diagnostic radiation exposures

6 Personal behaviors and exposures: Smoking; alcohol consumption; illicit drug use; overweight/underweight; folic acid supplement use; domestic violence; eating disorders; exposure to infections; exposures to chemicals and other environmental toxins; consumption of over-the-counter medications; hyperthermia (e.g., from sauna use)
However, the best evidence for the effectiveness of specific components of preconception care is seen when the focus was on a single intervention and often not in the context of improving pregnancy outcomes. For example, effectiveness documented by the U.S. Preventive Services Task Force for interventions related to smoking, alcohol misuse, and obesity are based on studies of interventions delivered in primary care settings that was not complicated by the additional delivery of other components of preconception care $[56,61,66]$. One study reported the effectiveness of comprehensive preconception care but inferences for the United States are limited because the setting of intervention delivery was in Hungary [75].

\section{Priorities for preconception care and preconception health}

The immediate priority is to ensure that evidence-based preconception interventions are implemented to further improve infant and maternal pregnancy outcomes. Many national professional organizations have developed and published CPGs for specific components of preconception care. For example, the American Diabetes Association developed CPGs to be started before pregnancy for women with preconception diabetes [28]. The American Association of Clinical Endocrinologists has developed preconception CPGs for women with hypothyroidism [34]. CPGs have also been developed for women being treated with teratogenic medications to guide the transition to safer medications. CPGs for women using antiepileptic drugs or oral anticoagulants have been developed by the American Academy of Neurology [50], the American Heart Association, and the American College of Cardiologists, respectively [44, 46]. Guidelines, recommendations, and strategies for reducing alcohol misuse and prevention of fetal alcohol syndrome have been developed and published by the U.S. Public Health Service, U.S. Preventive Service Taskforce, ACOG, and the National Taskforce on Fetal Alcohol Syndrome and Fetal Alcohol Effects [55-59].

However, moving forward towards more universal preconception care is not without its challenges. There is no national policy, nor do standard tools exist, for the delivery of these services. Some have suggested that challenges could be overcome by promoting preconception health to all women of reproductive age at each and every encounter with the health care system. The generally recommended mechanisms would include risk assessment (screening), health promotion (education and counseling), and intervention or referral. However, the existing recommendations to provide these three essential components have not been translated into practical tools for action and decision-making in the clinical setting. Stated another way, primary care providers do not have the tools they need to implement what is known to work for improving preconception health.

\section{Challenges and opportunities}

Whereas clinical practice and the promotion of preconception care services could potentially be shaped by guidelines, widespread adoption of the guidelines requires a more active approach [76, 77]. The literature on diffusion of innovation and translation of research into practice clearly indicates that changing primary care providers' knowledge, attitudes, and practices requires multiple steps including consolidation and distillation of guidelines, active organizational support, clinically relevant decision tools, use of quality improvement techniques, and performance monitoring [78, 79]. A growing body of research indicates that providers are more likely to engage in evidence-based practices following 
Table 2 Selected preconception risk factors for adverse pregnancy outcomes for which clinical practice guidelines have been developed
- Folic acid. Daily use of vitamin supplements containing folic acid has been demonstrated to reduce the occurrence of neural tube defects by two thirds [17-24]

- Rubella seronegativity. Rubella vaccination provides protective seropositivity and prevents the occurrence of congenital rubella syndrome [25-27]

- Diabetes (preconception). The three-fold increase in the prevalence of birth defects among infants of women with type 1 and type 2 diabetes is substantially reduced through proper management of diabetes [28-31]

- Hypothyroidism. The dosages of Levothyroxine ${ }^{\mathrm{TM}}$ required for treatment of hypothyroidism increases in early pregnancy. Levothyroxine ${ }^{\mathrm{TM}}$ dosage needs to be adjusted for proper neurologic development [32-34]

- HIV/AIDS. If HIV infection is identified before conception, timely treatment can be administered and women (or couples) can be given additional information that can influence the timing of the onset of pregnancy [35-41]

- Maternal phenylketonurea (PKU). Women diagnosed with PKU as infants have infants with mental retardation. However, this adverse outcome can be prevented when mothers adhere to a low phenylalanine diet before conception and continue it throughout their pregnancy [42, 43]

- Oral anticoagulant. Warfarin, which is used for the control of blood clotting, has been demonstrated to be a teratogen. To avoid exposure to warfarin during early pregnancy, medications can be changed to a nonteratogenic anticoagulant before the onset of pregnancy [15, 44-46]

- Anti-epileptic drugs. Certain anti-epileptic drugs are known as teratogens. Before conception, women who are on a regimen of these drugs and who are contemplating pregnancy should be prescribed a lower dosage of these drugs [15, 47-51]

- Isotretinoins (Accutane $\mathbb{R}$ ): Use of isotretinoins in pregnancy to treat acne results in miscarriage and birth defects. Effective pregnancy prevention should be implemented to avoid unintended pregnancies among women with childbearing potential who use this medication [15, 52-54]

- Smoking. Preterm birth, low birthweight, and other adverse perinatal outcomes associated with maternal smoking in pregnancy can be prevented if women stop smoking during early pregnancy. Because only $20 \%$ of women successfully control tobacco dependence during pregnancy, cessation of smoking is recommended before pregnancy [55-58]

- Alcohol misuse. No time during pregnancy is safe to drink alcohol, and harm can occur early, before a woman has realized that she is or might be pregnant. Fetal alcohol syndrome and other alcohol-related birth defects can be prevented if women cease intake of alcohol before conception [59-64]

- Obesity. Adverse perinatal outcomes associated with maternal obesity include neural tube defects, preterm delivery, diabetes, cesarean section, and hypertensive and thromboembolic disease. Weight loss before pregnancy reduces these risks [15, 65-69]

- STD. Chlamydia trachomatis and Neisseria gonorrhea have been strongly associated with ectopic pregnancy, infertility, and chronic pelvic pain. STDs during pregnancy might result in fetal death or substantial physical and developmental disabilities, including mental retardation and blindness [70, 71]

- Hepatitis B. Vaccination is recommended for men and women who are at risk for acquiring hepatitis B virus (HBV) infection. Preventing HBV infection in women of childbearing age prevents vertical transmission of infection to infants and eliminates risk for infection and sequelae, including hepatic failure, liver carcinoma, cirrhosis, and death [72-74] participation in quality improvement projects (e.g., rapid improvement cycles or collaborative groups). The federally funded Health Disparities Collaborative, the Perinatal Care and Patient Safety Collaboratives, and similar quality improvement efforts for community health centers demonstrate how such approaches are being used to better serve low-income and uninsured patients.

The need to develop innovative approaches to deliver and finance bundles of preconception interventions must be viewed as a high priority. However, although strong evidence exists for many preconception care interventions and shows they are effective, discussion continues regarding the benefits of delivering comprehensive preconception care $[16,80$,
81], and the effectiveness or added value of "packaging" or "bundling" these interventions remains to be determined. For example, preconception care interventions could potentially be bundled into behavioral modification services (e.g., smoking and alcohol cessation, weight control, exercise), screening and assessment (e.g., vaccines, general physical examination), and specialized care (e.g., management of diabetes and hypertension). Alternatively, interventions could be bundled into visits (e.g., do $\mathrm{x}$ at each well-woman visit, do y every 2 years, do $\mathrm{z}$ only for women at risk). Some evidence already suggests that bundling could be of added value. For example, an evaluation of the National Centers of Excellence in Women's Health found that, compared with 
other settings, women received better-quality primary health care at those centers having better integrated and coordinated services [82]. However, more such research, focused specifically on integration of preconception care components into primary care, is clearly warranted.

Efforts to promote healthy behavior and improve service delivery should be accompanied by improvements in health care coverage and financing for women of childbearing age. Affordability of care is a major concern for many women [83], and more can be done to improve access to preconception care. Many women under age 65 are uninsured, including $40 \%$ of poor women, one third of near-poor women (with income between $100 \%$ and $200 \%$ of the federal poverty level), $50 \%$ of women with disabilities, and $29 \%$ of young women ages 19-24 years [84]. Expanding health care coverage for low-income women, through public programs such as Medicaid, Medicaid waivers, the State Children's Health Insurance Program (SCHIP), is particularly important. Medicaid offers particularly important opportunities. In 2003, $12 \%$ of all women of childbearing age (15-44 years) and $37 \%$ of poor women in that age group relied on Medicaid for health care coverage [83]. Many low-income women do not, however, qualify for Medicaid because they do not have children under age 18 , are not over age 65 , or are undocumented. As states seek to expand Medicaid coverage to low-income, uninsured adults, women of childbearing age should receive high priority.

Although two thirds of women in Medicaid are of childbearing age [19-44, 85], many additional low-income women do not qualify for Medicaid benefits under current state eligibility rules unless they are pregnant. Without coverage before and between pregnancies, low-income women typically miss preventive visits [83]. Recognizing these gaps and missed opportunities for prevention, 21 states have developed special programs (under federal Medicaid waivers) that cover some women who do not otherwise qualify for Medicaid, particularly to offer family planning and interconception care. Specifically, these states extend eligibility to women who lose coverage after the birth of a baby or starting a job, while other states offer family planning coverage based on income status to men and/or women [86]. An evaluation of "family planning waiver" projects prepared for the federal Center for Medicare and Medicaid Services (CMS) found that they resulted in significant savings to both the federal and state governments [87]. Greater potential savings and prevention, however, could undoubtedly result if states offered more preconception risk screening, health promotion, and interventions; to do so, however, states need permission from the federal government to include such services in their waivers or need for Congress to approve interconception care as an optional benefit.

Finally, special attention should be given to the continuing, and sometimes increasing, racial gap in poor outcomes, especially in terms of access to services, and quality of care. These priorities can potentially complicate decision-making for public health policy. The best evidence of intervention effectiveness is often based on studies of health care systems. However, in developing programs and policies for the delivery of preconception services, one must consider the fact that poor access to health care can be a major determinant of health disparities.

\section{Preconception care: the next maternal and child health frontier}

The significant improvements in infant and maternal pregnancy outcomes during the past 40 years have resulted largely from the intensified focus on family planning in the 1960s and 1970s, on child health in the 1970s and 1980s, and on prenatal care in the 1980s and 1990s. Over the past 40 years, many public health and clinical care providers and their organizations have also recognized that, although it is important to offer family planning services to prevent unplanned pregnancies, it is not enough to worry about a pregnant woman's health only during her pregnancy or a child's health only after its birth, because many of the factors that contribute to the mother's and child's health can be identified and often successfully managed before pregnancy.

Today, the greatest opportunities for further improvement in pregnancy outcomes - in improving the health of women and their children-lie in prevention strategies that must be implemented prior to conception to be effective. In 1989, the U.S. Public Health Service Expert Panel identified preconception care as an essential part of prenatal care [88]. National organizations of health professionals, such as the AAP, ACOG, and the American Academy of Family Physicians (AAFP), all recommend specific components of preconception care that should be delivered within the context of health care systems $[15,89]$. The time has come to move forward to the next maternal and child health frontier of "prevention" by acting on the recommendations of professional organizations and implementing scientifically proven interventions to further improve pregnancy outcomes.

Action is urgently required in an array of clinical settings, in health promotion campaigns, and in academic research settings. Because of the wide range of interventions included under the umbrella of preconception care, such interventions may be delivered in both primary care and specialty care practices. However, opportunities also exist to improve preconception health through wellness care, through maintenance care for women with chronic health conditions associated with increased preconception risk (e.g., maternal diabetes), and in settings where women seek medical support for one specific risk such as smoking or obesity. In addition, more research is needed to understand how a women's 
motivation for healthy behavior can be used to initiate the reduction of a number of preconception risks. For example, comparison of concurrent versus sequential interventions for smoking and weight control requires additional clarification [90].

Above all, health care providers and health agencies must understand that early prenatal care is too late for many women and babies. In particular, some evidence-based interventions recommended for implementation during pregnancy could be more effective and beneficial if implemented before conception. For example, although smoking cessation is recommended for all pregnant women, more than one attempt to stop may be necessary to achieve success. Only about $20 \%$ of pregnant women who smoke are able to stop smoking during pregnancy [90]. Starting smoking cessation treatment — and successfully completing it—should be recommended before pregnancy is begun. Similarly, the only definitive way of preventing fetal alcohol syndrome is to stop drinking even before pregnancy. In the same manner, HIV testing and genetic counseling are recommended during pregnancy, but additional options are available to women who use these interventions prior to conception, including the decision not to become pregnant.

\section{Conclusion}

There is ample evidence that individual elements of preconception care work. Equally important, however, is the evidence that some interventions work best and others only work if provided before pregnancy. Given these realities, to further improve perinatal outcomes, the United States must commit to improving preconception health and to providing preconception care to all women of reproductive age. Even though sufficient knowledge and evidence is present to take action now, further efforts are needed to identify best practices and the most effective means of delivering integrated preconception services.

\section{References}

1. United States Department of Health, Education, and Welfare. Infant, fetal, and maternal mortality: United States-1963. Washington, DC: The Department; 1966.

2. United States Department of Health and Human Services. Health United States, 2004. Hyattsville, MD: The Department; 2004.

3. Centers for Disease Control and Prevention. Healthier mothers and babies. MMWR 1999;48:849-58.

4. Centers for Disease Control and Prevention. Birth: final data for 2002. National Vital Statistics Reports 2003;52.

5. Correa-Villasenor A, et al. The Metropolitan Atlanta Congenital Defects Program: 35 years of birth defects surveillance at the Centers for Disease Control and Prevention. Birth Defects Res 2003;67:617-24.

6. Centers for Disease Control and Prevention. Advance report of final mortality statistics, 1980. Monthly Vital Statistics Report 1983;32 Suppl.
7. Centers for Disease Control and Prevention. Deaths: leading causes for 2002. National Vital Statistics Reports 2005;53.

8. Danel I, et al. Magnitude of maternal morbidity during labor and delivery: United States, 1993-1997. Am J Public Health 2003;93:631-4.

9. United States Department of Health and Human Services, Health Resources and Services Administration, Maternal and Child Health Bureau. Women's health USA 2002. Rockville, MD: The Department; 2004.

10. Centers for Disease Control and Prevention. Alcohol consumption among women who are pregnant or who might become pregnantUnited States, 2002. MMWR 2004;53:1178

11. Besculides M, Laraque F. Racial and ethnic disparities in perinatal mortality: applying the perinatal periods of risk model to identify areas for intervention. JAMA 2005;97:1128-32.

12. Cai J, Hoff GL, Dew PC, Guillory VJ, Manning J. Perinatal periods of risk: analysis of fetal-infant mortality rates in Kansas City, Missouri. Matern Child Health J 2005;9:199-205.

13. Burns PG. Reducing infant mortality rates using the perinatal periods of risk model. Public Health Nurs 2005;22:2-7.

14. March of Dimes Birth Defects Foundation. March of Dimes Updates: Is early prenatal care too late? Contemp Ob/Gyn 2002;12:54-72.

15. American Academy of Pediatrics and the American College of Obstetricians and Gynecologists. In: Gilstrap L, Oh W, editors. Guidelines for perinatal care. 5th ed. Washington, DC, 2002.

16. Korenbrot CC, et al. Preconception care: A systematic review. Mater Child Health J 2002;6:75-88.

17. United States Public Health Service. Recommendations for the use of folic acid to reduce the number of cases of spina bifida and other neural tube defects. MMWR 1992;41(RR14).

18. Centers for Disease Control and Prevention. Effectiveness in disease and injury prevention use of folic acid for prevention of spina bifida and other neural tube defects-1983-1991. MMWR 1991;40:513-6.

19. United States Preventive Services Task Force. Screening for neural tube defects. Guide to clinical preventive services. 2nd ed. 1996, pp. 473-6.

20. American College of Obstetricians and Gynecologists. Clinical management guidelines for obstetrician-gynecologists. Committee Opinion No. 44 (replaces Committee Opinion No. 252, March 2001). Obstet Gynecol 2003;102:203-13.

21. American College of Obstetricians and Gynecologists Committee on Obstetrics: Maternal and Fetal Medicine. Folic acid for the prevention of recurrent neural tube defects. Committee Opinion No. 120, March 1993. Int J Gynaecol Obstet 1993;42:757.

22. Institute of Medicine Food and Nutrition Board. Dietary reference intakes for folate and other B vitamins. Washington, DC: National Academies Press; 1998.

23. Institute of Medicine Food and Nutrition Board. Dietary reference intakes for Thiamin, Riboflavin, Niacin, Vitamin B6, Folate, Vitamin B12, Pantothenic acid, Biotin, and Choline. Washington, DC: National Academies Press; 2000.

24. Lumley J, et al. Periconceptional supplementation with folate and(or multivitamins for preventing neural tube defects. Cochrane Database Syst Rev 2001;CD001056.

25. Centers for Disease Control and Prevention. Control and prevention of rubella: evaluation and management of suspected outbreaks, rubella in pregnant women, and surveillance for congenital rubella syndrome. MMWR 2001;50(RR12).

26. United States Preventive Services Task Force. Screening for rubella. Guide to clinical preventive services. 2nd ed. 1996.

27. American College of Obstetricians and Gynecologists. Rubella vaccination. Committee opinion no. 281, December 2002. Int J Gynaecol Obstet 2003;81:241. 
28. American Diabetes Association. Preconceptional care of women with diabetes. Diabetes Care 2004;27 Suppl:S76-8.

29. Kitzmiller JL et al. Preconception care of diabetes, congenital malformations, and spontaneous abortions (technical review). Diabetes Care 1996;19:514-41.

30. American College of Obstetricians and Gynecologists Committee on Technical Bulletins. Diabetes and pregnancy. Technical Bulletin No. 200, December 1994 (replaces No. 92, May 1986). Int J Gynaecol Obstet 1995;48:31-9.

31. Centers for Disease Control and Prevention. Strategies for reducing morbidity and mortality from diabetes through health-care system interventions and diabetes self-management education in community settings. MMWR 2001;50(RR16).

32. Helfand M, United States Preventive Services Task Force. Screening for subclinical thyroid dysfunction in nonpregnant adults: a summary of the evidence for the United States Preventive Services Task Force. Ann Intern Med 2004;40:128-41.

33. American College of Obstetricians and Gynecologists. Thyroid disease in pregnancy. Clinical management guidelines for Obstetrician-Gynecologists. Practice bulletin no. 37, August 2002. Obstet Gynecol 2002;100:387-96.

34. American Association of Clinical Endocrinologists, AACE Thyroid Task Force. Medical guidelines for clinical practice for the evaluation and treatment of hyperthyroidism and hypothyroidism. Endocr Prac 2002;8:457-69.

35. Centers for Disease Control and Prevention. Revised guidelines for HIV counseling, testing, and referral. Revised recommendations for HIV screening of pregnant women. MMWR 2001;50(RR19).

36. United States Public Health Service Task Force. Recommendations for use of antiretroviral drugs in pregnant HIV-1 - infected women for maternal health and interventions to reduce perinatal HIV-1 transmission in the United States. MMWR 2002;51(RR18):1-38.

37. American College of Obstetricians and Gynecologists. Human immunodeficiency virus infections in pregnancy. Int $\mathrm{J}$ Gynaecol Obstet 1997;57:73-80.

38. American College of Obstetricians and Gynecologists Committee on Ethics. Human immunodeficiency virus: ethical guidelines for obstetricians and gynecologists. Obstet Gynecol 2001;97 Suppl:16.

39. Institute of Medicine. Reducing the odds: Preventing perinatal transmission of HIV in the United States. Washington, DC: National Academy Press; 1999.

40. Institute of Medicine. Make prenatal HIV testing part of routine care. AIDS Alert 1998;13:137-8.

41. Brocklehurst P, Volmink J. Antiretrovirals for reducing the risk of mother-to-child transmission of HIV infection. Cochrane Database Syst Rev 2002;CD003510.

42. Phenylketonuria: Screening and Management. NIH Consensus Statement Online 2000 October 16-18:17, 1-27. Available at: URL: http://consensus.nih.gov/2000/2000Phenylketonuria113 html.htm

43. American College of Obstetricians and Gynecologists Committee on Genetics. Maternal phenylketonuria. Int J Gynaecol Obstet 2001;72:83-4.

44. American College of Obstetricians and Gynecologists Committee on Practice Bulletins-Obstetrics. Thrombembolism in pregnancy. Int J Gynaecol Obstet 2001;75:203-12.

45. American College of Obstetricians and Gynecologists. Preventing deep venous thrombosis and pulmonary embolism. Am Fam Physician 2001;63:2279-80.

46. Hirsh J, et al. American Heart Association/American College of Cardiology Foundation guide to warfarin therapy. Circulation 2003;107:692-711.

47. American College of Obstetricians and Gynecologists. Seizure disorders in pregnancy Educational bulletin no. 231. Int J Gynec Obstet 1997;56:279-86.
48. Barrett C, Richens A. Epilepsy and pregnancy: report of an Epilepsy Research Foundation Workshop. Epilepsy Res 2003;52:147-87.

49. Crawford P, et al. Best practice guidelines for the management of women with epilepsy. The Women with Epilepsy Guidelines Development Group. Seizure 1999;8:201-17.

50. Quality Standards Subcommittee of the American Academy of Neurology. Practice parameter: management issues for women with epilepsy (summary statement). Neurology 1998;51:9448.

51. Morrell MJ. Guidelines for the care of women with epilepsyConsensus conference-Current clinical practice. Neurology 1998;51Suppl:S21-7.

52. Centers for Disease Control and Prevention. Accutane-exposed pregnancies-California, 1999. MMWR 2000;49:28-31.

53. Perlman SE, et al. Caring for women with childbearing potential taking teratogenic dermatologic drugs - guidelines for practice. J Reprod Med 2001;46Suppl:153-61.

54. Perlman SE, et al. "Be smart, be safe, be sure." The revised Pregnancy Prevention Program for women on isotretinoin. J Reprod Med 2001;46Suppl:179-85.

55. United States Department of Health and Human Services, Public Health Service. Clinical Practice Guideline: Treating tobacco use and dependence. Washington, DC: The Department; 2000.

56. United States Preventive Services Task Force. Counseling: tobacco use Guide to Preventive Services, 3rd edition, Periodic Updates. Available at: URL: http://www.ahrq.gov/clinic/uspstf/uspstbac .htm

57. Hopkins DP, et al. Task Force on Community Preventive Services. Reviews of evidence regarding interventions to reduce tobacco use and exposure to environmental tobacco smoke. Am J Prev Med 2001;20Suppl:16-66.

58. American College of Obstetricians and Gynecologists. Smoking cessation during pregnancy. Educational bulletin no. 260, September 2000. Int J Gynaecol Obstet 2001;75:345-8.

59. Weber MK, et al. National Task Force on Fetal Alcohol Syndrome and Fetal Alcohol Effect. Defining the national agenda for fetal alcohol syndrome and other prenatal alcohol-related effects. MMWR 2002;51(RR14):9-12.

60. United States Preventive Services Task Force. Screening and behavioral counseling interventions in primary care to reduce alcohol misuse: recommendation statement. Ann Intern Med 2004;140:554-6.

61. Whitlock EP, et al. United States Preventive Services Task Force. Behavioral counseling interventions in primary care to reduce risky(harmful alcohol use by adults: a summary of the evidence for the United States Preventive Services Task Force. Ann Intern Med 2004;40:557-68.

62. American College of Obstetricians and Gynecologists. Substance abuse in pregnancy. Technical Bulletin No. 195, July 1994 (replaces No. 96, September 1986). Int J Gynaecol Obstet 1994;47:7380.

63. Stratton K, Howe C, Battaglia FC, editors, Committee to Study Fetal Alcohol Syndrome. Institute of Medicine. Fetal Alcohol Syndrome: Diagnosis, epidemiology, prevention, and treatment. Washington, DC: National Academies Press; 1996.

64. Bonnie RJ, O'Connell ME, editors; Committee on Developing a Strategy to Reduce and Prevent Underage Drinking. Institute of Medicine. Reducing Underage Drinking: A collective responsibility. Washington, DC: National Academies Press; 2004.

65. United States Department of Health and Human Services, Public Health Service, National Institutes of Health, National Heart, Lung, and Blood Institute Obesity Education Initiative. Clinical Guidelines on the Identification, Evaluation, and Treatment of Overweight and Obesity in Adults: The Evidence Report. Bethesda (MD): The Department, 1998. NIH Publication No. 98-4083. 
66. United States Preventive Services Task Force. Screening for obesity in adults: recommendations and rationale. Ann Intern Med 2003;139:930-2.

67. Institute of Medicine. Subcommittee on nutritional status and weight gain during pregnancy. Washington, DC: National Academy Press; 1990.

68. Kramer MS. Energy/protein restriction for high weight-for-height or weight gain during pregnancy. Cochrane Database Syst Rev 2000;CD000080.

69. American College of Preventive Medicine Practice. Policy statement: weight management counseling of overweight adults. Am J Prev Med 2001;21:73-8.

70. Centers for Disease Control and Prevention. Chlamydia trachomatis genital infections-United States, 1995. MMWR 1997;46:1938 .

71. Centers for Disease Control and Prevention. Gonorrhea-United States, 1998. MMWR 2000;49:538-42.

72. Centers for Disease Control and Prevention. Hepatitis B vaccination-United States, 1982-2002. MMWR 2002;51:549_ $52,63$.

73. Gunn RA, et al. Integrating hepatitis, STD, and HIV services into a drug rehabilitation program. Am J Prev Med 2005;29:2733.

74. Centers for Disease Control and Prevention. A comprehensive immunization strategy to eliminate the transmission of hepatitis B virus infection in the United States. Recommendations of the Advisory Committee on Immunization Practices (ACIP) part I-immunization of infants, children, and adolescents. MMWR 2005;54(RR-16):1-23.

75. Czeizel AE. Ten years of experience in periconceptional care. Eur J Obstet Gynecol Reprod Biol 1999;84:43-9.

76. Moos MK. Preconceptional wellness as a routine objective for women's health care: An integrative strategy. J Obstet Gynecol Neonatal Nurs 2003;32:550-6.

77. Jack BW, et al. Addressing preconception risks identified at the time of a negative pregnancy test. A randomized trial. J Fam Pract 1998;47:33-8.
78. Rodgers BD, Rodgers DE. Efficacy of preconception care of diabetic women in a community setting. J Reprod Med 1996;41:4226.

79. Lomas J. Retailing Research: Increasing the role of evidence in clinical services for childbirth. Milbank Q 1993;71:439-76.

80. Barash JH, Weinstein LC. Preconception and prenatal care. Prim Care 2002;29:519-42.

81. Brundage SC. Preconception health care. Am Fam Physician 2002;65:2507-14.

82. Henderson JT, et al. The role of physician gender in the evaluation of the National Centers of Excellence in Women's Health: test of an alternate hypothesis. Women's Health Issues 2004;14:130-9.

83. Kaiser Family Foundation. Women and health care: Key findings from the women's health survey. Washington, DC: The Foundation; 2005.

84. Kaiser Family Foundation. Women's Health Policy Fact Sheet: Women's Health Insurance Coverage, November 2004.

85. Kaiser Family Foundation. Medicaid's Role for Women. Issue Brief on Women's Health Policy, November 2004.

86. Edwards J, Bronstein J, Adams K. Evaluation of Medicaid Family Planning Demonstrations. The CAN Corporations Contract No. 752-2-415921. Sponsored by the Centers for Medicare and Medicaid Services, U.S. Department of Health and Human Services.

87. National Association of State Medicaid Directors. Review of Medicaid Family Planning Expansion Waivers, 2004. Available at: URL: www.nasmd.org.

88. USPHS- US Public Health Service Expert Panel on the Content of Prenatal Care. Caring for Our Future: The Content of Prenatal Care. Washington, DC: US Dept of Health and Human Services, 1989.

89. Petrie K, Frey KA, editors. Preconception Care/Infertility. Kansas City, Mo: American Academy of Family Physicians, 1998. Monograph 234.

90. Spring B, Pagoto S, Pingitore R, Doran N, Schneider K, Hedeker D. Randomized controlled trial for behavioral smoking and weight control treatment: effect of concurrent versus sequential intervention. J Consult Clin Psychol 2004;72:785-96. 